\title{
Media Desain Komunikasi Visual Sebagai Penunjang Promosi Pada SMK Yuppentek 7 Tangerang
}

\author{
Muhammad Arief Mujahid*, Muhammad Jamaludin Hafiz ${ }^{2}$, Adelia Mutiara Sari ${ }^{3}$ \\ ${ }^{1}$ Program Studi Teknik Informatika Fakultas Sains dan Teknologi Universitas Raharja \\ ${ }^{2}$ Program Studi Manajemen Informatika Fakultas Sains dan Teknologi Universitas Raharja \\ ${ }^{3}$ Program Studi Sistem Informasi Fakultas Sains dan Teknologi Universitas Raharja \\ Email : ${ }^{1}$ *arief.mujahid@ raharja.info, ${ }^{2}$ jamaludin@ raharja.info, ${ }^{3}$ adelia.mutiara@ @aharja.info
}

\begin{abstract}
ABSTRAK
Sekolah Menengah Kejuruan (SMK) Yuppentek 7 Tangerang adalah sebuah sekolah yang berada dibawah naungan yayasan usaha peningkatan pendidikan teknologi yang didirikan pada tahun 2010. Dengan memiliki empat jurusan yang diantaranya Teknik komputer jaringan (TKJ), Multimedia (MM), Farmasi dan keperawatan. Sekolah tersebut saat ini menghadapi sebuah permasalahan dalam menyebarkan promosi tentang sekolah tersebut karena media penunjang yang digunakan saat ini hanya sebatas brosur saja yang berisi promosi kurang lengkap dan tidak up to date. Hal tersebut dapat tidak tercapainya target siswa baru yang diharapkan setiap tahunnya. Dengan melihat permasalahan yang dihadapi maka sekolah tersebut membutuhkan sebuah media penujang promosi yang diantaranya adalah media berupa y banner, brosur, poster dan media flyer yang seluruh media tersebut. Tujuan dari penelitian ini yaitu untuk memperkenalkan sekolah tersebut kepada masyarakat luar agar tertarik untuk mendaftarkan ke sekolah tersebut. Metode untuk melakukan penelitian agar mendapatkan datadata terkait yaitu observasi, wawancara dengan pihak sekolah pada bagian kesiswaan pada SMK Yuppentek 7 Tangerang dan studi pustaka. Adapun dalam rancangan desain komunikasi visual tersebut menggunakan konsep desain yaitu layout kasar, layout komprehensif dan final artwork. Dengan dukungan rancangan media tersebut menggunakan software yaitu Adobe Illustrator CS6 dan Adobe Photoshop CS6. Sehingga dengan menggunakan media komunikasi visual tersebut untuk memberikan promosi secara lengkap bagi masyarakat dan juga siswa yang ingin bergabung di sekolah tersebut.
\end{abstract}

Kata Kunci - SMK, Promosi, Sekolah, Siswa.

\section{ABSTRACT}

Vocational High School (SMK) Yuppentek 7 Tangerang is a school under the auspices of a technology education improvement business foundation which was founded in 2010. It has four majors including Network Computer Engineering (TKJ), Multimedia (MM), Pharmacy and Nursing. The school is currently facing a problem in spreading promotions about the school because the supporting media currently used are only brochures which contain incomplete and not up-to-date promotions. This can not achieve the target of new students expected every year. By looking at the problems faced, the school needs a media to support promotion which includes media in the form of banners, brochures, posters and media flyers that are all media. The purpose of this study is to introduce the school to the outside community so that they are interested in registering for the school. The method for conducting research in order to obtain related data is observation, interviews with the school in the student section at SMK Yuppentek 7 Tangerang and literature study. As for the design of the visual communication design using design concepts, namely rough layout, comprehensive layout and final artwork. With the support of the media design using software, namely Adobe Illustrator CS6 and Adobe 
Photoshop CS6. So by using the visual communication media to provide a complete promotion for the community and also students who want to join the school.

\section{Keywords - SMK, Promotion, School, Student.}

\section{PENDAHULUAN}

Media komunikasi visual menjadi sebuah yang memiliki kekuatan untuk dapat menarik masyarakat dengan berisikan pesan dalam bentuk visualisasi yang mudah dipahami sehingga suatu lembaga pendidikan dapat dikenal secara luas oleh masyarakat. SMK Yuppentek 7 adalah sebuah sekolah kejuruan yang berlokasi di Jl. Perintis kemerdekaan No.1 Cikokol. Kota Tangerang memiliki empat jurusan unggulan diantaranya teknik komputer jaringan, multimedia, farmasi dan keperawatan. Saat ini media promosi yang digunakan oleh sekolah tersebut sebatas menggunakan brosur yang dinilai kurang efektif karena terbatasnya promosi yang disampaikan. Sehingga membutuhkan media komunikasi visual lainnya untuk menunjang promosi sekolah tersebut agar dapat dikenal secara luas kepada masyarakat di lingkup wilayah Kota Tangerang maupun di wilayah lainnya yang menjadi sasaran dari sekolah tersebut.

Media komunikasi visual menjadi sebuah media desain yang dihasilkan dari sebuah rasionalitas yang berlandaskan pengetahuan dan berrsifat pragmatis ${ }^{[1]}$. Maka dengan dukungan media komunikasi visual akan memperkenalkan SMK Yuppentek 7 Tangerang kepada masyarakat secara luas dan kepada siswa untuk mempromosikan sekolah tersebut sebagai salah satu bagian dari pemasaran dari suatu lembaga pendidikan kepada masyarakat secara luas ${ }^{[2]}$. Dengan merancang beberapa media komunikasi visual sebagai sarana promosi SMK Yuppentek 7 adalah , y banner, brosur, poster dan media flyer.

Agar hasil desain komunikasi visual dapat dinikmati oleh masyarakat secara luas maka diperlukan kualitas desain dengan dukungan software penunjang desain komunikasi visual yaitu meenggunakan adobe illustrator yang digunakan untuk penggunaan pembuatan editor grafis untuk pembuatan vektor desain ${ }^{[3]}$ serta untuk meningkatkan kualitas foto agar ketika diimplementasikan ke dalam media desain maka menggunakan adobe photoshop yang digunakan sebagai pengeditan foto atau gambar dengan penggunaan beberapa efek yang dibutuhkan. ${ }^{[3]}$

Sehingga dengan rancangan media komunikasi visual tersebut maka akan meningkatkan citra / image dari sekolah SMK Yuppentek 7 agar dapat dikenal oleh masyarakat secara luas, meningkatnya pendaftar siswa disetiap tahun ajaran baru dan dapat mencapai target yang diinginkan oleh pihak sekolah setiap tahunnya.

\section{METODE PENELITIAN}

Adapun dalam penelitian tersebut untuk memperoleh data dan informasi yang terkait dengan penyusunan penelitian guna mendapatkan bahan yang dibutuhkan serta mengeni software yang digunakan dalam perancangan media desain komunikasi visual pada SMK Yuppentek 7 adalah :

1. Metode Pengumpulan Data

Metode pengumpulan data ini dilakukan dengan beberapa tahapan diantaranya adalah metode observasi, wawancara serta studi pustaka.

2. Perancangan Media Desain Komunikasi Visual

Perancangan media komunikasi visual berbentuk desain ini menggunakan pengolahan dengan menggunakan software Adobe Illustrator Cs6 untuk pembuatan layout dan menggunakan software Adobe Photoshop Cs6 untuk pengolahan foto.

3. Konsep Desain

Agar perancangan media komunikasi visual sesuai dengan rencana dan kebutuhan maka konsep desain yang digunakan adalah layout kasar, layout komprehensif dan final artwork. 


\section{Literature Review}

Literature review adalah sebuah acuan dengan merujuk pada penelitian sebelumnya yang menjadi bahan evaluasi dari beberapa referensi untuk penelitian tersebut. Berikut ini terdapat beberapa artikel sebelumnya yang terkait dengan penelitian yang dilakukan oleh penulis adalah

Penelitian yang dilakukan oleh Widada, dkk. $(2020: 107)^{[4]}$ Dalam judul penelitian "Media Komunikasi Visual Sebagai Penujang Promosi Pada SMK Excellent 1 Tangerang" penelitian tersebut menjelaskan - Dengan desain produk tersebut sering digunakan oleh sekolah untuk mempromosikan sekolah tersebut. Desain grafis atau rancangan grafis merupakan suatu proses komunikasi yang menggunakan tulisan, bentuk dan gambar yang bertujuan untuk menghasilkan suatu informasi yang akan di sampaikan. Adapun dengan arah dari rancangan media desain tersebut adalah agar dapat digunakan untuk mempromosikan sekolah tersebut. Lembaga pendidikan merupakan sekolah pendidikan formal untuk semua agama. Media promosi yang digunakan lembaga pendidikan tersebut belum terbarui secara informasi karena masih menggunakan brosur. Dengan adanya penelitian ini media promosi untuk sekolah tersebut akan dapat menarik perhatian di lingkup masyarakat untuk mengetahui informasi sekolah tersebut.

Penelitian yang dilakukan oleh Aryani, dkk. $(2020: 33)^{[5]}$ Dalam judul penelitian "Desain Media Promosi dan Komunikasi Pada Yayasan Al-Fityan School Tangerang” penelitian tersebut menjelaskan - dengan didasari sebuah perkembangan informasi dan diiringi juga dengan perkembangan teknologi yang berkembang dengan baik. Maka akan mempercepat untuk mensosialisasikan media komunikasi visual kepada masyarakat secara luas sehingga dapat membuat persaingan dalam dunia promosi semakin ketat. Sehingga diperlukan sebuah produk yang lebih menarik. Tujuan untuk memberikan daya tarik masyarakat dalam mempromosikan media produk.

Penelitian yang dilakukan oleh Andriyanto dan Dianarti Muhyani. (2019:233) ${ }^{[6]}$ dalam judul penelitian "Desain Media Promosi dan Komunikasi Visual Pada Yayasan SMK Islam Baidhaul Ahkam Kota Tangerang" penelitian tersebut menjelaskan melalui media gambar, warna, dan teks informasi menjadi lebih jelas dan menarik. Khususnya dalam bidang publikasi, multimedia menjadi salah satu media pendukung dalam penyampaian informasi yang efektif, serta lebih menarik dalam penyajiannya. Dari waktu ke waktu, kebutuhan masyarakat terhadap desain yang kreatif, efisien, dan efektif semakin bertambah.Perkembangan dunia pendidikan yang semakin pesat, menyebabkan semakin banyaknya fasilitas dan keunggulan yang harus dipromosikan untuk bersaing dengan sekolah lain khususnya pada yayasan SMK Islam Baidhaul Ahkam.

Penelitian yang dilakukan oleh Immaniar, dkk. $(2017: 280)^{[7]}$ dalam judul penelitian "Desain Komunikasi Visual Sebagai Sarana Promosi Perguruan Tinggi" penelitian tersebut menjelaskan - Desain Komunikasi Visual Sebagai Sarana Promosi merupakan sebuah project yang mencoba memaparkan sebuah proses perancangan media untuk menginformasikan suatu pesan berkenaan dengan upaya promosi sebuah institusi yang bergerak dalam bidang pendidikan yaitu STKIP Pasundan. Pemilihan STKIP Pasundan ini didasari atas pertimbangan bahwa institusi pendidikan ini memiliki potensi yang besar untuk bersaing dengan institusi pendidikan sejenis lainnya yang bergerak di bidang Sekolah Tinggi Keguruan dan Ilmu Pendidikan.

Penelitian yang dilakukan oleh Putra, dkk. $(2021: 104)^{[8]}$ dalam judul penelitian "Desain Komunikasi Visual Sebagai Media Promosi Kerajinan Koran "Linting Paper" Dari Narapidana di Rutan Gianyar". penelitian tersebut menjelaskan - Di Rutan Gianyar ada kerajinan koran yang bernama "Linting Paper" yang di buat oleh para narapidana yang ada disana, kerajinan tersebut memiliki keunikan tersendiri karena motifnya terbuat dari warna kertasnya bahkan tulisan-tulisan yang ada dikoran tersebut masih kelihatan. Akan tetapi kerajinan koran yang dibuat oleh narapidana tersebut belum dikenal oleh masyarakat sehingga perlu dipromosikan. Melihat permasalahan tersebut akhirnya penulis merancang penelitian 
mengenai permasalahan publikasi, untuk membantu mempromosikan kerajinan koran dari narapidana di Rutan Gianyar, maka diperlukan peranan dari media promosi.

\section{HASIL DAN PEMBAHASAN}

\subsection{Perencanaan Media}

Perencanaan media yang dilakukan oleh penulis sebagai media promosi untuk SMK Yuppentek 7 adalah dalam bentuk media komunikasi visual seperti y banner, brosur dan media flyer. Seluruh media desain tersebut akan berkonsepkan modern design karena memiliki konsep dan unsur desain yang mengikuti trend yang digunakan saat ini agar tertarik untuk masyarakat.

\subsection{Perencanaan Pesan (Konsep Kreatif)}

Perencanaan pesan adalah merencanakan atau menkonsepkan apa yang ingin disampaikan kepada masyarakat agar tertarik dan isi pesan tersebut mudah dipahami oleh seluruh elemen masyarakat. Dengan menggunakan ide - ide yang menarik dengan sebuah kalimat yang membuat ketertarikan dan sesuai dengan kebutuhan yang diinginkan maka sebuah perencanaan pesan yang matang pun akan mempengaruhi bagi SMK Yuppentek 7 agar memiliki citra atau image yang baik dari rancangan media komunikasi visual tersebut.

\subsection{Tujuan Visual}

Tujuan visual yang direncanakan pada tampilan rancangan desain y banner, brosur dan media flyer adalah untuk memberikan sebuah citra / image yang baik mengenai SMK Yuppentek 7 serta mempromosikan sekolah tersebut kepada masyarakat secara luas agar tertarik untuk bergabung di sekolah tersebut.

\subsection{Perencanaan Visual}

Perencanaan visual perlu dilakukan sebagai awalan dalam melakukan rancangan media desain komunikasi visual agar terlihat menarik bagi masyarakat luas. Dengan perencanaan tersebut memerlukan sebuah ide dan konsep kreatif dan bentuk layout yang disesuaikan dengan identitas SMK Yuppentek 7. Dengan menggunakan beberapa elemen desain yang umum digunakan seperti typography yang mudah terbaca, logo sekolah, warna - warna yang soft dan solid color. Sehingga dengan perpaduan tersebut desain akan memiliki nilai yang baik dan masyarakat akan tertarik.

\subsection{Konsep Desain}

Konsep desain adalah sebuah tahapan dalam proses pembuatan desain yang telah di konsepkan secara matang. Maka dari itu, terdapat beberapa konsep desain yang digunakan antara lain layout kasar, layout komprehensif dan Final Artwork.

\subsubsection{Layout Kasar}

Layout kasar adalah tahapan awal perencanaan dalam desain komunikasi visual dengan menggumpulkan ide-ide dan konsep desain yang tepat dengan menggambarkan dengan media sketsa yang berbentuk coretan dengan menggunakan pensil dan dibuat dengan warna hitam putih. Layout kasar perlu dilakukan sebelum memasukin tahapan proses desain dengan menggunakan software penunjang desain grafis. Berikut ini adalah layout kasar yang dibuat : 
1. Layout Kasar Brosur Halaman 1 dan 2

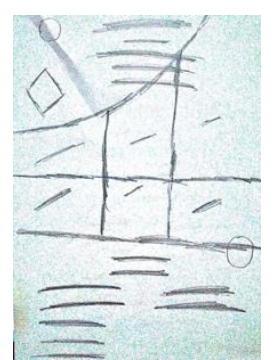

Gambar 1. Layout Kasar Brosur Halaman 1

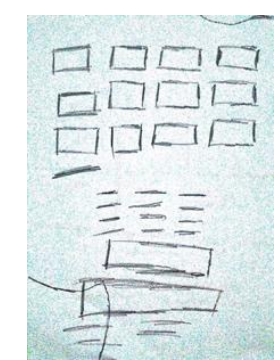

Gambar 2. Layout Kasar Brosur Halaman 2

2. Layout Kasar Spanduk Jurusan Sekolah dan Spanduk Selamat Datang Siswa/i
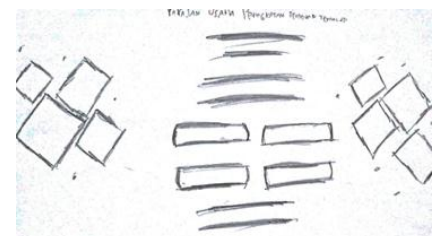

Gambar 3. Layout Kasar Spanduk Jurusan Sekolah

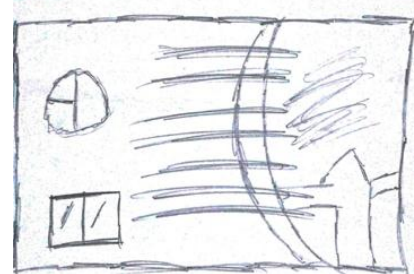

Gambar 4. Layout Kasar Spanduk Selamat Datang Siswa/I Baru

3. Layout Kasar Y banner dan Poster Promosi Sekolah

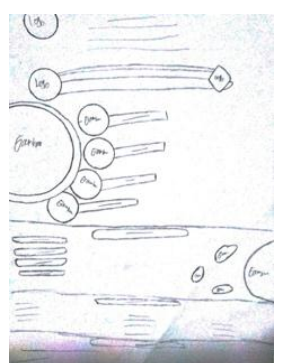

Gambar 5. Layout Kasar Y Banner Promosi Sekolah

4. Layout Kasar Flyer Promosi Sekolah

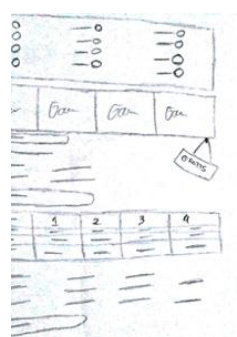

Gambar 7. Layout Kasar Flyer Promosi Halaman 1

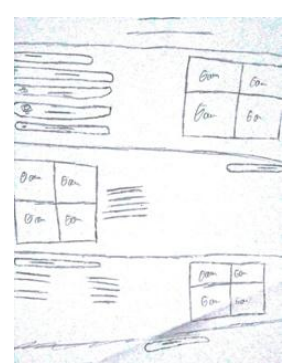

Gambar 6. Layout Kasar Poster Promosi Sekolah 


\subsubsection{Layout Komprehensif}

Layout komprehensif adalah tahapan untuk memulai merancang pembuatan layoutlayout desain grafis dengan menggunakan software penunjang desain grafis seperti adobe illustrator dan adobe photoshop akan tetapi dalam proses layout komprehensif tersebut masih terdapat mengalami beberapa perbaikan. Oleh karena itu berikut ini adalah layout komprehensif rancangan media komunikasi visual untuk promosi pada SMK Yuppentek 7 Tangerang :
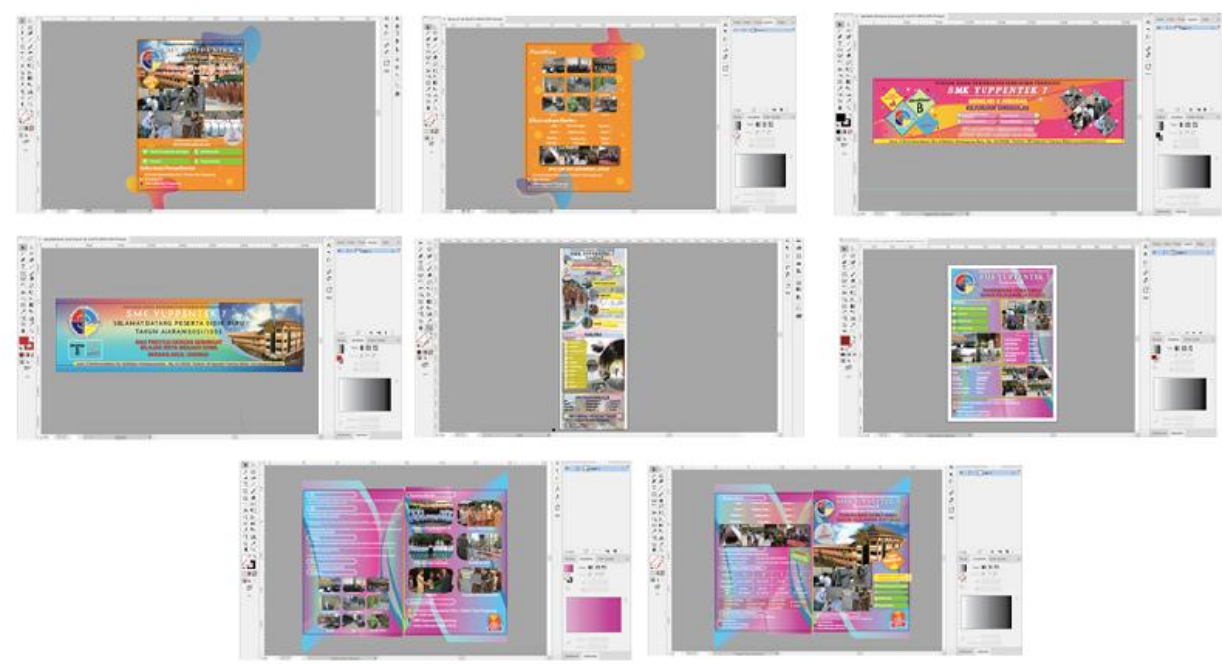

Gambar 9. Layout Komprehensif Media Promosi pada SMK Yuppentek 7 Tangerang

\subsubsection{Final Artwork}

Final artwork adalah tahapan proses desain yang sudah memasuki tahapan akhir dan rancangan media sudah siap memasuki proses pencetakan media. Berikut ini adalah rancangan akhir dari media desain tersebut :

1. Final Artwork Brosur Halaman 1

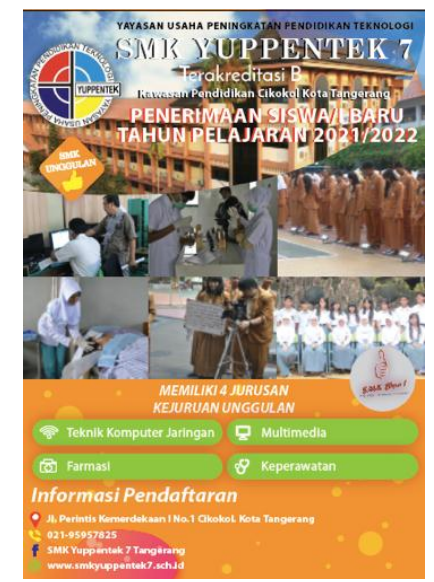

Gambar 17. Final artwork Brosur Halaman 1

Pada gambar 17 tersebut menjelaskan final artwork dari brosur halaman 1 sebagai media promosi untuk SMK Yuppentek 7 Tangerang. Dengan menampilkan image seputar kegiatan sekolah dan penjelasan jurusan dari sekolah tersebut dan beberapa contact person yang dapat dihubungi. Adapun ukuran yang digunakan dalam media tersebut adalah A4 yaitu $21 \mathrm{~cm} \mathrm{x} 29,7 \mathrm{~cm}$. 
2. Final Artwork Brosur Halaman 2

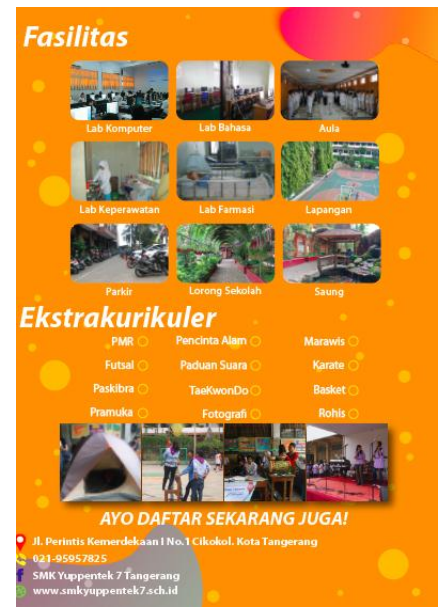

Gambar 18. Final artwork Brosur Halaman 2

Pada gambar 17 tersebut menjelaskan final artwork dari brosur halaman 2 sebagai media promosi untuk SMK Yuppentek 7 Tangerang. Dengan menampilkan image seputar fasilitas dan kegiatan ekstrakurikuler sekolah. Adapun ukuran yang digunakan dalam media tersebut adalah A4 yaitu $21 \mathrm{~cm}$ x $29,7 \mathrm{~cm}$.

3. Final Artwork Spanduk Jurusan

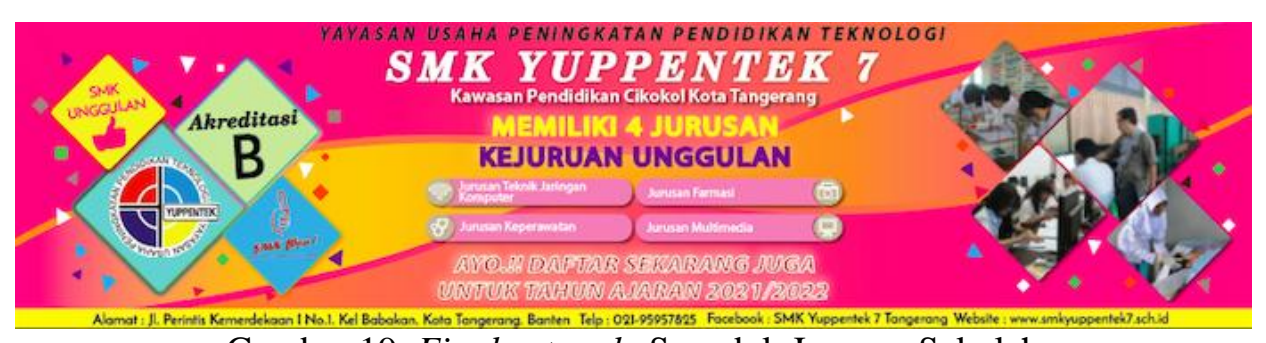

Gambar 19. Final artwork Spanduk Jurusan Sekolah

Pada gambar 19 tersebut menjelaskan final artwork spanduk jurusan sekolah yang menggambarkan beberapa jurusan yang tersedia di sekolah tersebut untuk bahan promosi kepada masyarakat dan siswa/I baru. Dengan memiliki empat jurusan unggulan yaitu teknik komputer jaringan, multimedia, farmasi dan keperawatan. Dengan menggunakan ukuran media yaitu $400 \mathrm{~cm}$ x $100 \mathrm{~cm}$.

4. Final Artwork Spanduk Selamat Datang siswa/i Baru

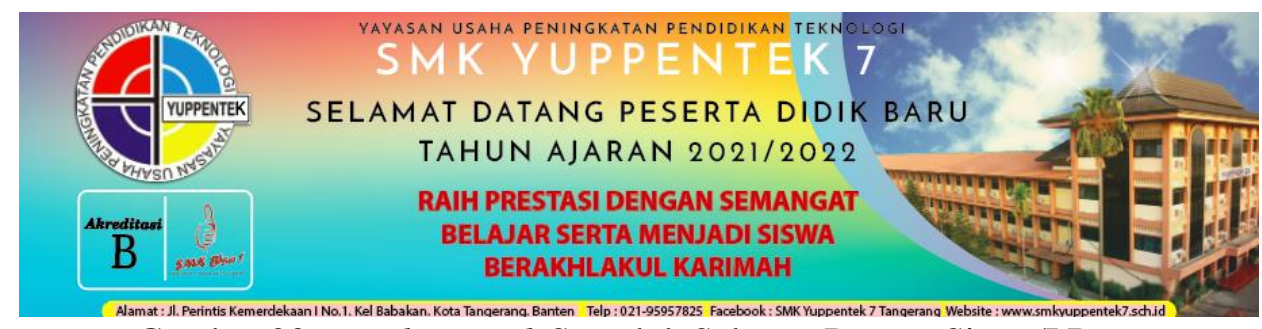

Gambar 20. Final artwork Spanduk Selamat Datang Siswa/I Baru 
Pada gambar 20 tersebut menjelaskan final artwork spanduk selamat datang siswa/I baru yang menggambarkan untuk menyambut siswa/I baru ditahun ajaran baru tersebut. Dengan menggunakan ukuran media yaitu $400 \mathrm{~cm}$ x $100 \mathrm{~cm}$.

\section{Final Artwork Y Banner}

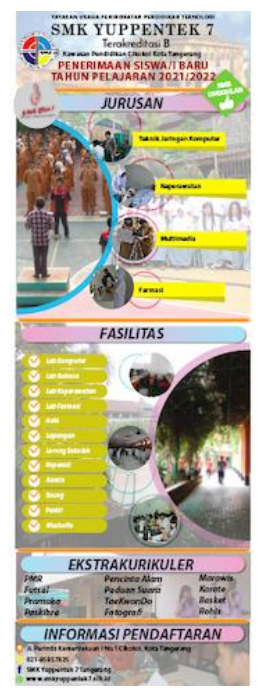

Gambar 21. Final artwork Y Banner

Pada gambar 21 tersebut menjelaskan final artwork y banner sebagai media promosi untuk sekolah. Dengan menampilkan image dari kegiatan sekolah dan menjelaskan mengenai jurusan sekolah, fasilitas sekolah, ekstrakurikuler dan informasi pendaftaran. Media tersebut menggunakan ukuran $160 \mathrm{~cm}$ x $60 \mathrm{~cm}$.

6. Final Artwork Poster Promosi

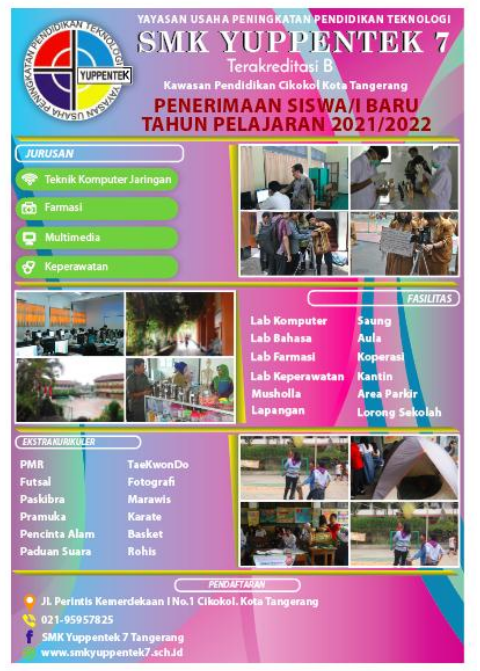

Gambar 22. Final artwork Poster Promosi

Pada gambar 22 tersebut menjelaskan final artwork poster promosi sekolah yang menjadikan bahan promosi untuk sekolah. Dengan menampilkan image dari kegiatan sekolah dan menjelaskan mengenai jurusan sekolah, fasilitas sekolah, ekstrakurikuler dan informasi pendaftaran. Media tersebut menggunakan ukuran $21 \mathrm{~cm}$ x $29,7 \mathrm{~cm}$. 


\section{Final Artwork Flyer Promosi Halaman 1}

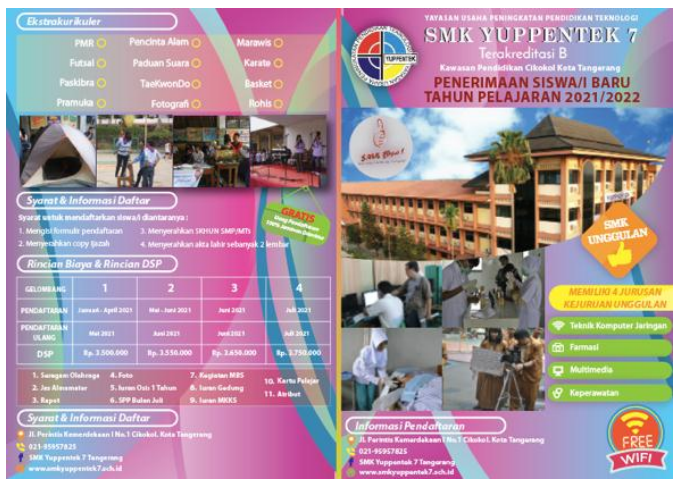

Gambar 23. Final artwork flyer promosi halaman 1

Pada gambar 23 tersebut menjelaskan final artwork dari media flyer promosi halaman 1 yang menjelaskan informasi mengenai jurusan sekolah. Image dari setiap jurusan yang tersedia di sekolah tersebut serta contact person dari sekolah tersebut. Selanjutnya, dibagian sebelah kiri media tersebut menjelaskan mengenai kegiatan yang diadakan oleh sekolah untuk pengembangan diri siswa/I, rician biaya, kelengkapan yang didapatkan ketika siswa tersebut mendaftar. Media tersebut menggunakan ukuran $21 \mathrm{~cm}$ $\mathrm{x} 29,7 \mathrm{~cm}$.

\section{Final Artwork Flyer Promosi Halaman 2}

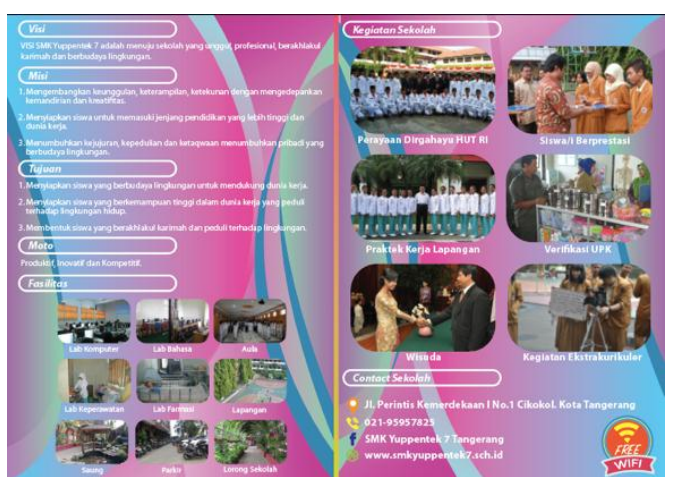

Gambar 24. Final artwork flyer promosi halaman 1

Pada gambar 24 tersebut menjelaskan final artwork dari media flyer promosi halaman 2. Dibagian sebelah kiri media menjelaskan mengenai visi dan misi SMK Yuppentek 7 Tangerang dan terdapat image dari beberapa fasilitas sarana penunjang kegiatan belajar mengajar disekolah tersebut. Dibagian sebelah kanan media menjelaskan beberapa image yang menhelaskan mengenai kegiatan sekolah tersebut.

\section{KESIMPULAN}

Kesimpulan yang didapat dari penelitian tersebut adalah dengan menggunakan media komunikasi visual seperti y banner, brosur, poster dan media sebagai media penunjang untuk promosi pada SMK Yuppentek 7 Tangerang. Maka promosi yang ditawarkan oleh sekolah tersebut dapat mudah tersampaikan kepada masyarakat. Baik skala wilayah Kota Tangerang maupun wilayah sekitar lainnya sehingga masyarakat mengetahui adanya keberadaan sekolah tersebut dan mengetahui seluruhnya mengenai lingkup SMK Yuppentek 7 dan menarik untuk siswa agar bergabung di sekolah tersebut. 


\section{SARAN}

Adapun saran yang dapat diberikan oleh penulis untuk perkembangan media kedepannya adalah agar tampilan media komunikasi visual dapat selalu up to date dan berbagai perubahan mengenai promosi yang ditawarkan oleh pihak sekolah tersebut. Sehingga promosi dapat dilakukan dengan lebih baik dengan menggunakan media komunikasi visual tersebut.

\section{DAFTAR PUSTAKA}

[1] Fadhila dan Asep Kadarisman. 2020. Perancangan Buku Seri Mengenai Pemahaman Dasar Proses Cetak Untuk Mahasiswa Desain Komunikasi Visual. Bandung : Universitas Telkom. Jurnal Art \& Design. Vol.7 No.2.

[2] Hasim, Dina. Nurhadi Kusumo. Sugiyanto. 2019. Pengaruh Pelayanan dan Promosi Tehadap Minat Konsumen Pada S Plus Indonesia. Tangerang Selatan : Universitas Pamulang. Prosiding Seminar Nasional Humanis.

[3] Jerwin, Langie Julio. Arie Salmon. Brave Angkasa Sugiarso. 2020. Animasi Interaktif Dua Dimensi Pedoman Gizi Seimbang. Manado : Universitas Sam Ratulangi. Jurnal Teknin Informatika. Vol.15 No.3.

[4] Widada, Sugeng. Karunia Suci Lestari. Nuryahya Ibrahim. 2020. Media Komunikasi Visual Sebagai Penujang Promosi Pada SMK Excellent 1 Tangerang. Tangerang : Universitas Raharja. Jurnal Mavib. Vol.1 No.1.

[5] Aryani, Diah. Jumilah Andriati. Suratna Sudirja. 2020. Desain Media Promosi dan Komunikasi Pada Yayasan Al-Fityan School Tangerang. Tangerang : Universitas Raharja. Jurnal Mavib. Vol.1 No.1.

[6] Andriyanto dan Dianarti Muhyani. 2019. Desain Media Promosi dan Komunikasi Visual Pada Yayasan SMK Islam Baidhaul Ahkam Kota Tangerang. Tangerang : Universitas Raharja. Jurnal Cerita. Vol. 5 No.2. ISSN : 2461 - 1417.

[7] Immaniar, Dewi. Reni Mulyani. Fitria Arnita. 2017. Desain Komunikasi Visual Sebagai Sarana Promosi Perguruan Tinggi. Tangerang : STMIK Raharja. Jurnal Sensi Vol.10 No.1. ISSN : 1978 - 8282.

[8] Putra, I Dewa Gede Agung. Gde Bagus Udayana. I Gede Agus Indram Bayu Artha. 2021. Desain Komunikasi Visual Sebagai Media Promosi Kerajinan Koran "Linting Paper" Dari Narapidana di Rutan Gianyar. Bali : Institut Seni Indonesia. Jurnal Amarasi. Vol.2 No.1. 